\title{
Analysis of Complimenting in L1 vs. L2 Written Discourse: A Case Study of Iranian Students Writing Review Letters
}

\author{
Gholam Reza Zarei \\ English Language Center, Isfahan University of Technology, Isfahan 84156-83111, Iran \\ Email: grzarei@cc.iut.ac.ir
}

\begin{abstract}
The present study was carried out to compare and contrast complimenting as used in L1 (Farsi) and L2 (English) writings of Iranian students in a foreign language learning context. For the purpose, sixty five university senior students majoring in English and taking the specialized course called "essay writing" were selected for the study. First, they were instructed how to write review letters on their classmates' essays in both $\mathrm{L} 1$ and $\mathrm{L} 2$ and then their letters were analyzed on the basis of the framework provided by Johnson and Roen (1992), and Chafe and Danielwicz (1987). The results indicated that Iranian students (female and male) did not make significantly different uses of $\mathrm{L} 1$ and $\mathrm{L} 2$ complimenting in terms of form and strategies. Also, the gender of the addressees was not accommodated to by the addressors differently as regards the use of form and strategies of complimenting in $\mathrm{L} 1$ and $\mathrm{L} 2$. The results suggest that $\mathrm{L} 1$ and $\mathrm{L} 2$, if used under some formal class based conditions, tend to become maximally similar, showing no transfer of L1 potentiality into L2.
\end{abstract}

Index Terms - L1, L2 learning politeness, complimenting, face threatening act, written discourse

\section{INTRODUCTION}

While Iranians naturally acquire Farsi as their L1, they learn English (L2) as a foreign language, having no social function as such. Learning a language in the classroom is almost largely considered to be different from naturalistic learning. The two kinds of learning diverge on psycholinguistic, educational, and sociolinguistic grounds. The difference largely relates to the presence of L1 knowledge. In other words, adults learning L2 seem to carry over their L1, say, pragmatic patterns to L2 environment. In this line, some studies in Iran (Yeganeh, 1996; Shams, 1997; Yarmohammadi, 1995) have shown male and female divergences in the use of L1 (Farsi) complimenting. SalmaniNodoushan (2007) has also demonstrated that conversational strategies used in Persian are sex dependent. This study is thus an attempt to reveal whether Iranian male and female students of English language also function differently in L1 and L2 context. This will cast light over the role L1 can have in learning another language especially in a context where L2 is just formally taught and learned and has no social function. To make it clear more, we may maintain that this study can illuminate the competing roles these two variables, i. e., L1 and classroom context, can play in learning a foreign language as regards the use of complimenting as a pragmatic issue.

\section{BACKGROUND}

As communication subsumes a lot more than culturally neutral information, there is a need to raise L2 learners' consciousness in characteristically distinct features of two languages. One important interface of L1-L2 is the use of politeness strategies. Brown and Levinson's (1989) sociolinguistic theory of politeness incorporates all that is referred to as mutual respect. In Brown and Levinson's term, paying a compliment is a positive politeness strategy that addresses the hearer's positive face. Having borrowed "face", they define it as something that is emotionally invested, and that can be lost, maintained or enhanced, and must be constantly attended to in interaction. Wierzbicka (1991) defines politeness, as a person's effort to respect other's right, autonomy and privacy. Politeness strategies, according to her, are context-specific and may vary drastically from one culture to another. The significance of this aspect of language renders it essential to be studied further.

In regard to the learners of a second language, Kasper (1992) asserts that learners' pragmatic knowledge of native language and culture can exert influence on their comprehension, production and learning of L2 pragmatic information. Farerch and Kasper (1984) view pragmatic knowledge as a part of language user's communicative competence to perform and understand intentionality under contextual and discoursal constraints. Pragmatic knowledge of L1 influencing L2 performance can be diverse (Odlin, 2003) and under certain conditions where there is little interlingual convergence can cause misinterpretations and misunderstanding (Bu, 2010). Among the pragmatic knowledge studied, complimenting is believed to be one particular case which is characteristically distinct across different cultures. This is to verify the fact that learning a language is a lot more than form which involves special pragmatic features playing a crucial role in communication (Hymes, 1974; Labov, 1970). 
More specifically, complimenting as a politeness strategy is defined by Holmes (1988) as '... a speech act which explicitly or implicitly attributes credit to someone other than the speaker, usually the person addressed, for something good (possession, characteristic, skill, etc.) which is positively valued by the speaker and hearer (p. 446)'.

A good number of studies have so far attempted to clarify the structural and functional nature of the phenomenon 'complimenting' (Johnson \& Roen, 1992; Iwai \& Rinnert, 2002; Mojica, 2002; Huth, 2006; Karimnia \& Afgari, 2010). Some of these studies which have focused on foreign language learning (e.g., Huth, 2006; Bu, 2010; Karimnia \& Afgari, 2010) have documented that L2 learners often go their own way and display L1 dependent orientations. Despite a good number of studies around, it seems that they have not been able to reach consensus as to the nature of complimenting.

Complimenting is used both in spoken and written modes. These two modes, however, differ on some grounds, e.g., in the manners of production and the forms of the two modes. Though spoken mode is usually given the priority in language learning, the written mode also enjoys a special position among educated people. And since writing manifests one's particular personality, and leaves recorded signs, it is believed to be highly important among academics. Thus, this study aims to probe into complimenting in written mode. Different genres of written mode abound. But one, which best serves the purpose here is letter genre. Chafe and Danielwicz (1987) consider this genre 'as the continuum between conversational, spoken language, and highly formal, academic written language (p. 7)'. The rhetorical situation in composing a letter shares certain characteristics with conversational situations such as real, known, directly addressed audience with whom the writer interacts on a regular basis. It also shares characteristics with more formal academic writing situations such as serious topics for an academic purpose, time to deliberate and to select a more varied and adequate vocabulary and complex structures. Thus, letter genre seems appropriate for the purpose. However, what distinguishes this study from other studies is the particular role "instruction" can play in learning a foreign language in general and sociolinguistic patterns in particular. In relation to instruction three positions can be reviewed. The first position believes that formal instruction may affect the learner's knowledge of only some aspects of language (Felix, 1981; Krashen, 1982). Some other aspects are believed not to come under the influence of instruction. The second position claims that instruction can help with the achievement of proficiency (e.g., Celce-Murcia, 1992), correcting errors and focusing on specific aspects of language and only with early stages of language acquisition (Higgs \& Clifford, 1982). The third group finds instruction essential in the process of second language acquisition. They think instruction can help speed up the rate of acquisition and the development of variational features of L2, which lead to acquisition (Ellis, 1990). As shown in the above positions, almost all studies so far available have dealt with non-pragmatic aspects of L2. Since the pragmatic side is associated with the notion of appropriacy for interpersonal communication, it is necessary to direct some studies in this way to unfold the functioning mechanisms involved. Moreover, as L1 is learned naturally and L2 just in the classroom, the study can elucidate the interaction between the two.

Complimenting as one pragmatic feature plays an important role in the establishment of rapport between people, in particular of different cultures. And as Iranian learners of English language learn their L2 in the classroom with no native speakers' interaction and also only by Iranian teachers, this study attempts to cast light over the way they would incorporate this important sociolinguistic feature in their language. Therefore, the study seeks to explore:

1. if Iranian learners of English (male and female) organize their L1 and L2 differently in terms of form and strategies of complimenting; and

2. if Iranian English learners realize their L1 and L2 differently with different audiences (male and female)?

\section{METHOD}

\section{A. Subjects}

The subjects of this study comprised 65 male/female university senior students selected from among 86 students. In order to keep the students' L2 proficiency level constant so that it would not affect their performances on the letters, they were given a TOEFL test. Then the letters written by those students whose test scores were not at the extreme ends of the score continuum were selected for the study. Each subject under this study had a score within the range of one SD above and below the mean score. The mean score and the SD for the TOEFL test were 45.35 and 12.5, respectively (out of 100). Thus, 65 subjects out of 86, whose L2 scores were within the range of 32.84-57.83, were selected. The subjects were all majoring in English at Kashan University, Iran, and they were taking "essay-writing" as one of the required courses for completing their studies for BA in TEFL. They had already taken some skill courses in reading, writing, grammar, and oral skills as well as some content courses in linguistics, language teaching, and English literature during a period of about three and a half years. All the subjects were native speakers of Farsi.

\section{B. Data Collection}

The data came from a setting where the activities were taken to be part and parcel of the classroom and the requirement of the course. The students were required to write an English essay on a topic every week. The teacher corrected and commented on the papers. After midterm they were required to read their classmates' papers and write an English letter to the writer of the essay, commenting on the essay. Before embarking on the main job, the teacher gave them a sample letter. The sample letter included all necessary steps to be taken in writing the review letters. To do the task, the students' essays were randomly distributed among class members. Then, they were guided to read their peer's papers, evaluate them, write comments on the papers, and finally write an English letter to their partners (on the basis of 
Roen \& Johnson's model, 1992). One week after the English letters had been written, they were required to write a Farsi letter to the same partners. They were asked to do two things in their letters: (1) explain what they liked about the paper; and (2) suggest ways that the essays could be improved. They were also asked to take the following points into account while writing the letter: to write about (1) the paper under review (the product); (2) the writer of the paper (the addressor); (3) the acts undertaken in writing the paper (the process); (4) the impact of the paper on the reader (the rhetorical effect). The official teacher of the class undertook the responsibility and implemented the plan. The researcher had no intervening role in this respect. To avoid 'observer's paradox (Labov, 1970) and to obtain objective data without injecting self into the data which may confound the results, the teacher stayed out of the students' sight.

\section{Data Analysis}

The subjects' review letters (both L1 and L2) were analysed based on the model provided by Johnson and Roen (1992), and Chafe and Danielwicz (1987). The classification of elements for the analysis is as follows:

1. Form of compliment: positive evaluative terms (P.E.T.): This part included all those terms which attribute some credit to an addressee, e.g., your first paragraph sounds "interesting".

2. Discourse strategies: In this part, discourse strategies are particularly the complimenting strategies used to build up the whole text. They are classified as follows: (1) compliments redressing specific criticisms and suggestions; this strategy involves pairing a compliment (CL) with a specific face-threatening act (FTA) to soften the force of FTA, e.g., your opinions are good; however, you need to elaborate more. (2) Compliments redressing global FTA; this strategy involves the establishment of rapport with the addressee by the use of opening or closing positive politeness strategies, e. g., (opening the letter) I would like to tell you that I enjoyed your letter. (3) Framing strategies; this is the opening and closing discourse strategies (politeness strategies) taken together. In this case, a letter opening with positive comments followed by a global FTA, and ending with positive comments is said to have a framing strategy (CL $\rightarrow$ Global $\mathrm{FTA} \rightarrow \mathrm{CL}$ ).

The letters were thus analyzed for the above mentioned categories and their frequencies were determined for further evaluation.

\section{RESULTS}

On the basis of the above-mentioned classification adopted from Johnson and Roen (1992) and Chafe and Danielwicz (1987), the data were extracted and then subjected to different statistical operations, including the calculation of means and mean ranks, comparison of mean ranks, comparison of frequencies $\left(\mathrm{x}^{2}\right)$ and calculation of the degree of variation (SD) of each category among male and female subjects.

\section{A. Analysis of Form of Compliments}

The analysis involved counting up the number of positive evaluative terms (P.E.T) used by every writer within his/her text both in L1 and L2. This measure is more sensitive than using the syntactic criteria because it gets more directly at the positive evaluation that is at the heart of complimenting (Johnson \& Roen, 1992). Table 1. Displays that women used a mean rank of 35.01 evaluative terms per text in L2 and 36.02 in L1, and men used a mean rank of 30.65 and 32.07, respectively in L2 and L1. Although the mean and mean rank of positive evaluative terms used by women is slightly more in both languages, the statistical analysis revealed no significant difference between male and female subjects as addressors across the two languages. Also, both women and men used more evaluative terms in their L1, but they are not statistically different from their L2. The only important point is that women have shown more variations in their use of such terms, with the case being more salient in L1 (SD=2.06)

TABLE I.

MEAN FREQUENCY AND MEAN RANK OF PET AS USED BY THE GENDER OF WRITER

MEAN FREQUENCY AND MEAN RANK OF PET AS USED BY THE GENDER OF WRITER
\begin{tabular}{|l|l|l|l|l|l|l|l|}
\hline Writer & $\mathrm{N}$ & L2 Mean & L2 SD & L1 Mean & L1 SD & L2 Mean Rank & L1 Mean Rank \\
\hline Female & 35 & 3.97 & 1.44 & 4.02 & 2.06 & 35.01 & 36.02 \\
\hline Male & 30 & 3.56 & 1.19 & 3.7 & 1.7 & 30.65 & 32.07 \\
\hline L2 P: 0.3404 & P<.05 & L1 P: 0.45 \\
L2 \& L1 P: 0.38
\end{tabular}

There was also an interest in how the writers varied their language use for different audiences. As shown in table 2, female subjects writing to their own sexes used most P.E.T in both languages though to a slightly more degree in L2. In the same way, male subjects, though a bit less than female, used more evaluative terms when writing to their own sexes. Also, the addressees received more evaluative terms when addressed by their own sex. It must be noted in total this was used more in L2. However, the differences among the four mean ranks both in L1 and L2 and for the two together were not significant. 
TABLE II.

MEAN FREQUENCY AND MEAN RANK OF PET AS ADDRESSED TO DIFFERENT ADDRESSEES

\begin{tabular}{|c|c|c|c|c|c|c|c|}
\hline Writer/Addressee & $\mathrm{N}$ & L2 Mean & L2 SD & L1 Mean & L1 SD & L2 Mean Rank & L1 Mean Rank \\
\hline Female-Female & 18 & 4.44 & 1.58 & 5.05 & 1.8 & 41.39 & 43.2 \\
\hline Female-Male & 17 & 3.44 & 1.12 & 3.72 & 2 & 28.26 & 30.01 \\
\hline Male-Male & 17 & 3.76 & 1.20 & 4.01 & 1.5 & 33.24 & 36.08 \\
\hline Male-Female & 13 & 3.30 & 1.18 & 3.4 & 1.2 & 27.27 & 28.3 \\
\hline \multicolumn{8}{|c|}{ 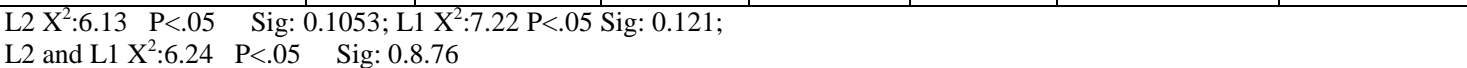 } \\
\hline
\end{tabular}

To sum up, it is evident that the greatest amount of complimenting (P.E.T.), though statistically not significant, was offered by women writers to women addressees. Male writers offered the least amount of complimenting to the female writers in both languages. The important point is that the writers accommodated to their own sexes more than the opposite sex. This finding can be explained by the fact that in Iran opposite sex interaction is very limited or better say not permitted.

\section{B. Analysis of Strategies of Complimenting}

Complimenting strategies in this study refer to the ways through which the writers construct their whole texts. As mentioned before, compliments are used to address both specific FTAs (criticisms and suggestions) and to address the global FTA (the act as a whole). In this part, the two strategies and their proportions of use along with gender differences in using them as employed by the subjects are presented.

1. Compliments redressing specific criticism and suggestions

Writers of letters most frequently relied on "good news/bad news pairing strategy" to redress specific (or local) FTAs. This strategy involves pairing a compliment (CL) with a specific (FTA) to soften the force of the FTA (CL+FTA). This good news bad news pairing strategy (CL+FTA), as shown in table 3, was used by women slightly more than by men in both languages. This was slightly more for females in L1. However, the statistical analysis revealed no significant difference. On the whole, male subjects made less use of this strategy irrespective of the addressee. Nonetheless, male subjects treated the opposite sex (female) more delicately whereas female subjects again kept off the opposite sex, and accommodated to their own sex more. It is noteworthy that female subjects acted more softly while either writing to female or to male subjects in both languages.

In sum, it can be inferred that the pattern of use for this strategy may explain the fact that women try to be more positive and less outspoken than men. Of course, men at the same time attempt to act more cautiously when addressing the opposite sex. However, statistical analyses of L1, L2, and both languages showed that the differences were not significant.

TABLE III.

FREQUENCY OF LOCAL STRATEGY AS USED BY GENDER OF WRITER AND ADDRESSEE

\begin{tabular}{|l|l|l|l|}
\hline Writer/Addressee & $\mathrm{N}$ & L2 \% & L1 \% \\
\hline Female-Female & 18 & 77.7 & 88.8 \\
\hline Female-Male & 17 & 64.7 & 76.47 \\
\hline Male-Male & 17 & 58.8 & 70.50 \\
\hline Male-Female & 13 & 61.53 & 76.92 \\
\hline Total Female & 35 & 71.42 & 82.8 \\
\hline Total Male & 30 & 60 & 73.3 \\
\hline Total & 65 & 66.1 & 78.4 \\
\hline L2 X ${ }^{2}: 1.74$, Sig:7.81, p<. 05; L1 X ${ }^{2}: 1.95$, Sig:8.7, p<.05 \\
L2 \& L1 X $: 2.8$, Sig:8.1, p<.05 \\
\hline
\end{tabular}

\section{Compliments redressing the global FTA}

To construct the texts at the most global levels, writers in addition to using local strategies to mitigate specific criticisms, used this particular compliment strategy as well. As writing a letter with comments and suggestions constitutes a potential global FTA, writers have to take an interpersonal rhetorical stance to redress the global FTA (Johnson \& Roen, 1992). To redress the global FTA, and build rapport, most writers use the strategy of opening the letter with one or more compliments; others frame the letter by both opening and closing it with compliments.

In this study, as table 4 shows, while most of the writers opened their letters with compliments (78\%) some more closed their letters with compliments $(84.6 \%)$ in L2. This was slightly more in the case of L1 for both opening and closing the letters, with closing compliments outweighing the opening. Although male subjects used specific complimenting strategy less than with women, they used the global strategy slightly more than women (66.6\%). This case is again occurring more with L1 writers (73.3\%). This may account for the fact that men are more globally oriented, and feel that once and all they can soften their harshness. Thus, for men opening or closing the letters with compliments rather than being concerned with every specific suggestion or criticism would suffice to sound interpersonally appropriate.

Table 4 shows that females, irrespective of their addressors, received this strategy more (both in L1 and L2 opening and closing compliments) than did the male addressees. Furthermore, women received more of this strategy from men 
(84.6\%) in L2 opening and 92.3\% in closing. The situation was similar in L1 as well. However, women accommodated to their own sex more than the opposite sex, though the difference is very slight across the two languages.

Finally, it can be concluded that with regard to the global strategy, male used slightly more of this strategy, indicating that men are more globally rather than locally oriented in addressing others appropriately. Moreover, women, contrary to men, again accommodated to their own gender more than they did to men. The general pattern across the two languages is almost identical, with a slight increase in the use of compliments in L1.

TABLE IV

FREQUENCY OF GLOBALAND FRAMING STRATEGIES AS USED BY GENDER OF WRITER AND ADDRESSEE

\begin{tabular}{|l|l|l|l|l|l|l|l|}
\hline \multirow{2}{*}{ Writer/Addressee } & \multirow{2}{*}{$\mathrm{N}$} & \multicolumn{2}{|l|}{ Opening strategy } & \multicolumn{2}{l}{ Closing strategy } & \multicolumn{2}{l|}{ Framing strategy } \\
\cline { 3 - 8 } & & L2\% & L1 \% & L2 \% & L1 \% & L2 \% & L1 \% \\
\hline Female-Female & 18 & 77.7 & 88.8 & 83.3 & 88.8 & 66.6 & 72.2 \\
\hline Female-Male & 17 & 76.4 & 88.23 & 82.3 & 88.1 & 64 & 70.5 \\
\hline Male-Male & 17 & 76.4 & 76.4 & 82.3 & 82 & 58 & 64.7 \\
\hline Male-Female & 13 & 84.6 & 84.6 & 92.3 & 92 & 76.6 & 84.6 \\
\hline Total female & 35 & 77.1 & 88.6 & 82.8 & 88.5 & 65.7 & 71.42 \\
\hline Total male & 30 & 80 & 80 & 86.6 & 86.6 & 66.6 & 73.3 \\
\hline Total & 65 & 78 & 84.6 & 84.6 & 87.6 & 66.15 & 72.3 \\
\hline
\end{tabular}

\section{Framing strategy}

The discourse strategy of both opening and closing with one or more compliments is a "compliment framing strategy" through which writers choose to enclose the FTAs with positive comments (CL+FTA+CL) (Johnson \& Roen, 1992). Results of this strategy (See Table 4) display that male subjects used slightly more of this strategy $(66.6 \%)$ as compared with female subjects in L2. The same pattern is also observable for L1. With regard to the gender of the addressee, female subjects received this strategy more than did male addressees in both languages. It must be noted that female subjects received more of this strategy when addressed by male subjects in both languages. While men used framing strategy more when addressing female subjects, female subjects did not receive them similarly. Female subjects again kept away from the opposite sex and accommodated to their own gender more. All in all, despite the fluctuations among the writers in using the global and framing strategies, the statistical analysis disapproved of any significant difference between them $\left(\mathrm{X}^{2}: 0.42\right.$; Sig:3.84; $\left.<<.05\right)$. Considering the gender of the addressees, it is also revealed that fluctuations in the use of the global strategy (the total of the opening, closing and framing strategies) are not statistically significant $\left(\mathrm{X}^{2}: 0.87\right.$; Sig:7.81; $\left.\mathrm{p}<.05\right)$.

In summary, the analysis of complimenting discourse strategies in letters across L1 and L2 provided evidence that gender of writer and addressee play a minor role in selection of both local and global strategies. In regard to local strategy (CL+FTA), more writers used this strategy for a female addressee. In other words, female addressees received local strategy more than did the male addressees. Furthermore, female subjects received this strategy from their own sex more than they received from male subjects. On the global level, men used this strategy (CL+FTA+CL) more than women did. But again it was female subjects who received strategy more, both from the opposite sex and from their own gender, indicating that females are treated with more respect. Though statistical analyses revealed no significant difference in use of these strategies by different subjects, the findings very roughly and marginally indicate some way that L1 (Farsi) is more comfortably used in providing compliments in the review letters. This can be partly due to the possible better command of the writers over L1.

\section{DISCUSSION AND CONCLUSION}

The findings of this research demonstrate a uniform pattern of gender based complimenting use both in terms of forms and strategies across both Farsi as writers' L1 and English as their L2. The patterns of language use reported in here suggest that both gender of the writer and that of the addressee play a minor role in complimenting in written discourse. This finding very clearly goes contrary to the findings of the study by Salmani-Nodoushan (2007), which attests to the sex dependency of the complimenting strategies in Farsi. It was also found that when men and women learn or produce a language in formal context and under similar conditions of classroom, they produce the same type of discourse, i.e., their discourse becomes maximally alike in both their native and non native language. In general, the points may show that classroom conditions can just let out certain semantic fundamentals which prevail in all languages (Goddard \& Wierzbicka, 2004; Wierzbicka, 2007) as L2 socio-pragmatic norms find a little chance to be materialized and L1 has to be formally used. In line with Huth (2006), the results may also lead us to gather that L1 and L2 interaction in the context of classroom has got its own inherent social nature.

Also, the results can be accounted for in a number of ways as follows. The first thing is that these students functioned in an Iranian context where all the participants were Iranians. Thus, it is not surprising to discover that they abide by some formal social rules promoted in Iranian contexts especially at the universities. As is known well, university students are strongly recommended, as is the case in the society, to avoid social interactions with the opposite sex. Of course this is expected to yield results different from what we have reached. But, as already claimed (Felix, 1981), instruction is not supposed to bear the same result as social interaction and it can affect only specific features of language. Instruction may thus affect the process (Higgs \& Clifford, 1982) or linguistic proficiency but not the 
pragmatic issues (Celce-Murcia, 1992). Another point is that the teachers were also all Iranians who could very restrictively approach their students only through the intermediary of the books, and the classroom did not provide the latitude for stronger social relations. Anyway, the findings of this study, however, do not verify the position taken by Towell and Hawkin (1994) and also by (Huth, 2006) that L1 transfer of properties in the area of discourse and functions of language into L2 is unavoidable.

Next point worth attention is that the results testify that the Persian writers of English make every attempt to remain polite, thus avoiding FTAs, which is almost generally the case in lots of world languages (e.g., Salamani-Nodoushan, 2008; Alfattah \& Ravindrantha, 2009). Moreover, the results support Johnson and Roen's (1992) and Poynton's (1989) claims that gender differences are less likely to occur in written discourse due to greater formality of the academic setting, the seriousness of topic, the written modality and the situational equality of the participants. In other words, gender differences may melt away when equality is achieved. As Poynton (1989) suggests 'the greater equality between interactants, the more likely they are to behave linguistically in parallel or symmetrical ways (p. 790)'. Though Poynton (ibid) refers to the finding in L1, we can generalize his idea to L2 and claim that equality in teaching and learning situation as well as in the type of activity disallow the transfer of L1 functional properties into L2. Beyond it, L1 is also modified so as to meet the formal demands of the classroom conditions. The immediate implication of this study is that gender differences may be more matter of upbringing and social and situational pressures than that of the genetic tendencies.

It must be noted that this study analyzed the forms and strategies of complimenting quantitatively rather than qualitatively. It is already accepted that a high quality language of respect and compliment can securely balance out the limits of quantity, thus breeding more satisfaction on the part of the addressee. This is to say that depth of emotions and affections in the words could certainly make a difference and a frequency based positive term and strategy cannot be considered anything more than suggestive.

\section{ACKNOWLEDGEMENT}

The author wishes to express his gratitude to Dr. A. Raheemi of Kashan University for data collection and Dr. F. Lak of Bushehr Persian Gulf University for statistical analyses.

\section{REFERENCES}

[1] Alfattah, M. H. A., \& B. K. Ravindranath. (2009). Politeness strategies in the English interlanguage requests of Yemeni learners. Iranian Journal of Language Studies (IJLS), 3.3, 249-266.

[2] Brown, P. \& S. Levinson. (1989). Politeness: Some universals in language use. Cambridge: CUP.

[3] Bu, J. (2010). A study of pragmatic transfer in compliment response strategies by Chinese learners of English. Journal of Language Teaching and Research, 1.2, 121-129.

[4] Celce-Murcia, M. (1992). Teaching English as a second language. Oxford: OUP.

[5] Chafe, W. \& J. Danielwicz. (1987). Properties of spoken and written language. Technical Report No.5, 28-40.

[6] Ellis, R. (1990). Instructed second language acquisition. Oxford: Basil Blackwell.

[7] Faerch, C. \& G. Kasper (1984). Pragmatic Knowledge: Rules and Procedures. Applied Linguistics, 5.3, 214-225.

[8] Felix, S. (1981). On the (in) applicability of Piagetian thought to language learning. Studies in Second Language Acquisition, 3.2, 201-220.

[9] Goddard, C. \& Wierzbicka. A. (2004). Cultural scripts: What are they and what are they good for? Intercultural Pragmatics 32, 153-166.

[10] Higgs, T. V. \& R. Clifford, R. (1982). The push toward communication. In Higgs, T.V. (Ed.), Curriculum Competence and the Foreign Language Teacher. The American Council on the Teaching of Foreign Languages, Foreign Language Education Series. Lincolnwood, IL: National Textbook.

[11] Holmes, J. (1988). Compliments and compliment responses in New Zealand English. Anthropological linguistics, 12, $445-508$.

[12] Huth, Th. (2006). Negotiating structure and culture: L2 learners' realization of L2 compliment response sequences in talk-ininteraction. Journal of Pragmatics, 38, 2025-2050.

[13] Hymes, D. (1974). Foundations in sociolinguistics: an ethnographic approach. Philadelphia: University of Pennsylvania Press.

[14] Iwai, C. \& Rinnert, C. (2002). Strategic solution of sociopragmatic problems in using world Englishes. In M. Swanson, D. McMurray \& K. Lane (Eds.), The proceedings of the 3rd Pan Asian Conference at JALT 2001 (PP. 881-887). Tokyo: JALT.

[15] Johnson, D. \& D. H. Roen. (1992). Complimenting and involvement in peer-reviews: gender variation. Language in society, 21.1,27-57.

[16] Karimnia, A. \& A. Afgari. (2010). On the applicability of cultural scripts in teaching L2 compliments. English Language Teaching, 3.3, 71-80.

[17] Kasper, G. (1992). Pragmatic transfer. Second language research, 8.3, 203-231.

[18] Krashen, S. D. (1982). Principles and practice in second language acquisition. Oxford: Pergamon.

[19] Labov, W. (1970). The study of language in social context. Studium generale, 20, 30-87.

[20] Mojica, L. A. (2002). Compliment giving among Filipino college students: an exploratory study. Asia Pacific Education Review, 3.1, 115-124.

[21] Odlin, T. (2003). Cross-linguistic influence. In C. J. Doughty \& M. H. Long (Eds.), the handbook of second language acquisition (pp. 436-486). Oxford: Blackwell Publishing Ltd.

[22] Poynton, C. (1989). Language and gender: making the difference. Oxford: OUP. 
[23] Salmani-Nodoushan, M.A. (2007). Iranian complainees' use of conversational strategies: A politeness study. Iranian Journal of Language Studies (IJLS), 1.1, 29-56.

[24] Salmani-Nodoushan, M.A. (2008). Persian requests: Redress of face through indirectness. Iranian Journal of Language Studies (IJLS), 2.3, 257-280.

[25] Shams, M. R. (1997). Gender, socioeconomic status, and politeness strategies. Unpublished master's thesis. Esfahan: Esfahan University.

[26] Towell, R. \& R. Hawkins. (1994). Approaches to second language acquisition. Bristol: The Lonunn Press.

[27] Wierzbicka, A. (1991). Cross-cultural pragmatics: the semantics of human interaction. Berlin: Mouton de Gruyter.

[28] Wierzbicka, A. (2007). Bodies and their parts: An NSM approach to semantic typology. Language Sciences, 29, 14-65.

[29] Yarmohammadi, L. (1995). Analysis of politeness forms in English and Persian: a socio-pragmatic approach. IJOAL, 21.1, 5767.

[30] Yeganeh, A. (1996). Gender, age and politeness: a cross-cultural study. Unpublished master's thesis. Esfahan: Esfahan University

Gholam Reza Zarei received his Ph.D. in Applied Linguistics from Isfahan University, Iran. He is currently teaching different courses at both undergraduate and graduate levels and has published some skill as well as content books and articles. 